\title{
Característica Epidemiológica da Violência Intrafamiliar contra o Idoso no Município de Iguatu-CE
}

\author{
Natália Bastos Ferreira ${ }^{1}$; Cleiton de Araújo Correia ${ }^{2}$; Raimundo Tavares de Luna Neto ${ }^{3}$; \\ Riani Joyce Neves Nóbrega ${ }^{4}$; Denise Maria Christofolini ${ }^{5}$
}

\begin{abstract}
Resumo: Objetivou-se conhecer o perfil epidemiológico da violência intrafamiliar sofrida pelo idoso no município de IguatuCE. Trata-se de um estudo exploratório, documental numa abordagem quantitativa. A coleta de dados ocorreu no mês de outubro de 2010. O instrumento da coleta de dados constituiu-se na análise de 14 fichas de registro de denúncias encaminhadas ao Centro de Referência Especializada da Assistência Social (CREAS). A pesquisa obedeceu a Resolução 196/96 tenso sido aprovada pelo Comitê de Ética da Faculdade Católica Rainha do Sertão. Percebeu-se que a faixa etária dos 71 a 80 anos é a mais vitimizada, sendo a negligência o tipo de violência mais percebido. O gênero predominante vitimizado pela violência foi o feminino sendo os filhos seus principais agressores. Em vista dos resultados é necessário que os profissionais de saúde, principalmente aqueles que atuam nas Unidades de Saúde da Família (UBS), estejam preparados para diagnosticarem suspeitas ou casos confirmados de maus tratos a idosos, além de maiores investimentos acerca da avaliação de riscos de maus-tratos, implementação de uma assistência multiprofissional com a integração com outros serviços de proteção e desenvolvimento de pesquisas que possam contribuir na geração de políticas públicas no intuito de minimizar o problema de maus-tratos contra os idosos.
\end{abstract}

Palavras-Chave: Epidemiologia; violência; idoso.

\section{Epidemiological characteristics of violence against the elderly in the municipality of Iguatu-CE}

\begin{abstract}
The objective of the epidemiological profile of domestic violence suffered by the elderly in the city of Iguatu - EC. This is an exploratory, documentary study a quantitative approach . Data collection occurred in October 2010. The instrument of data collection consisted in analyzing 14 registration file complaints forwarded to the Centre for Social Assistance Specialized Reference ( CREAS ). The research followed the Resolution 196/96 tense approved by the Ethics Committee of the Catholic Faculty Rainha do Sertão . It was noticed that the age group of 71-80 years is more victimized, being the kind of neglect seen more violence. The predominant genus victimized by violence was the female children being their main aggressors. In view of the results it is necessary that health professionals, especially those working in the Family ( UBS ) Health Units are prepared to diagnose suspected or confirmed cases of mistreatment of the elderly, as well as higher investments on the risk assessment maltreatment, implementation of a multidisciplinary care with integration with other services for protection and development of research that can contribute to the generation of public policies in order to minimize the problem of mistreatment of the elderly .
\end{abstract}

Keywords: Epidemiology; violence; elderly.

\footnotetext{
${ }^{1}$ Mestranda em Ciências da Saúde pela Faculdade de Medicina do ABC. Docente da Universidade Regional do Cariri (URCA) / Campus Avançado de Iguatu-CE; Endereço: Rua Brigadeiro Eduardo Gomes, 331, Planalto; CEP: 63500-000, Iguatu-Ce, Brasil. nataliabastosf@ hotmail.com

${ }^{2}$ Enfermeiro pela Universidade Regional do Cariri (URCA) / Unidade Descentralizada de Iguatu-CE

${ }^{3}$ Mestrando em Ciências da Saúde pela Faculdade de Medicina do ABC. Docente da Universidade Regional do Cariri (URCA) / Campus Avançado de Iguatu-CE;

${ }^{4}$ Enfermeira. Docente do Curso de Enfermagem da Universidade Regional do Cariri (URCA) - Unidade Descentralizada de Iguatu.

${ }^{5}$ Programa de Pós Graduação em Ciências da Saúde pela Faculdade de Medicina do ABC.
} 


\section{Introdução}

O envelhecimento ao decorrer da história da humanidade vem passando por um processo de mudanças de conceito e importância que foi se alterando de acordo com as culturas de cada país e época. Nos dias atuais, o aumento dessa população, não somente percebida em países desenvolvidos, em toda Europa e America do Norte, mas também em países em desenvolvimento como, por exemplo, no Brasil, vem se manifestando de maneira muito mais clara e perceptível em todos os seguimentos sociais.

O envelhecimento populacional é caracterizado pelo declínio da mortalidade infantil, pela diminuição de morte de adultos por infecção e pelo declínio da taxa de natalidade. Vem ocorrendo de forma relativamente rápida nas últimas décadas em países como o Brasil em que a população de mais de 65 anos cresceu de 2,8\% em 1960 para 5,1\% em 2000 e presume-se que no final de 2010 haja um aumento da taxa de 5,9\% e de 7,7\% em 2020 (NERI; YESSUDA, 2004).

Esse crescimento se deve a alguns fatores como o avanço nas pesquisas científicas, acesso aos serviços sócio-sanitários e a cura de algumas doenças, investimento das instituições públicas no combate às epidemias, as obras de saneamento básico, na melhoria das moradias, na melhoria da alimentação básica, fatores que tem possibilitado o aumento significativo da expectativa de vida (ARAÚJO; LOBO, 2009).

Juntamente com o envelhecimento da população, a violência contra o idoso vem crescendo passando a ser considerado um problema mundial que atinge toda a população independente dos fatores sociais, econômicos e culturais.

A violência contra idosos é responsável por elevados índices de morbimortalidade e se manifesta de diversas maneiras tais como a violência física, psicológica, autonegligência, negligência, abandono e exploração financeira. Ela é tida como uma das mais severas e desiguais formas de agressão, visto que há uma ampla relação de desigualdade do ponto de vista físico e psicológico. Isto ocorre devido aos déficits auditivo, visual, motor e cognitivo que o idoso apresenta (SANTOS et al, 2007).

Estudos realizados em vários países de diferentes culturas têm demonstrado que a violência contra o idoso abrange pessoas de todos os status sócio-econômicos, etnias e religiões. Freqüentemente, uma pessoa idosa sofre, ao mesmo tempo, vários tipos de violência e maus tratos. Assim sendo, a Organização Mundial de Saúde (OMS) entende por maus-tratos e negligência a ação única ou repetida, ou ainda a ausência de uma ação devida, que causa sofrimento ou angústia, e que ocorre em uma relação em que haja expectativa de confiança (SOUZA; FREITAS; QUEIROZ, 2007). 
Inquéritos populacionais conduzidos em diversas regiões do mundo têm apontado prevalências de abuso físico no ambiente doméstico em idosos que variam entre 1,2\% na Holanda e 18\% na Finlândia (MORAES; APRATTO JÚNIOR; REICHENHEIM, 2008).

Estudo feito pelo Instituto Brasileiro de Ciências Criminais (IBCCRIM), com base nas ocorrências registradas pela Delegacia de Proteção ao Idoso de São Paulo no ano 2000, mostra que $39,6 \%$ dos agressores eram filhos das vítimas; $20,3 \%$, seus vizinhos e 9,3\%, outros familiares. As ocorrências registradas com maior freqüência foram ameaças $(26,93 \%)$, seguidas de lesão corporal $(12,5 \%)$ e de calúnia e difamação $(10,84 \%)$. O estudo enfatizou ainda que parte das ocorrências foi retirada pelos idosos dias após a denúncia. Nos registros, esses idosos argumentavam a necessidade de viver com a família além do que a manutenção da queixa atrapalharia a convivência entre os familiares (RITT, 2007).

No Ceará, conforme dados da Secretaria da Ouvidoria Geral e do Meio Ambiente (SOMA), entre as denúncias feitas ao Serviço Especial de Defesa do Idoso (SEDI) e Alô-Idoso, em 2004, 32\% dessas denúncias eram de violência física, $20 \%$ de abandono, $16 \%$ de apropriação indébita de aposentadoria e 13\% de negligência (SOUZA; FREITAS; QUEIROZ, 2007).

Partindo dessas premissas surgiram algumas indagações expressas a seguir: Quais os tipos de violência mais praticados em idosos no município de Iguatu-Ceará? Quem são os principais agressores? Quais as medidas legais adotadas pelo poder judiciário no tocante a punição desses agressores? Como a enfermagem pode contribuir para que essa população seja melhor assistida em seu contexto bio-psico-social?

A abordagem desse tema se deve ao fato da violência ser um problema que traz grandes consequiências para a saúde, não só das pessoas agredidas, mas também de todos os envolvidos.

Chama-nos a atenção a omissão que acontece tão freqüentemente por parte dos idosos agredidos devido ao sentimento de culpa e vergonha, medo de retaliação ou ainda represália do agressor, muitas vezes sendo este o próprio familiar.

A relevância desse estudo se apresenta pelo fato de proporcionar a sociedade acadêmica, inclusive o corpo de profissionais da enfermagem enriquecimento sobre o tema, pois servirá de subsídio para o conhecimento do número de idosos que sofrem com a violência na cidade de IguatuCe, sensibilizando assim não somente os profissionais da área da saúde, mas também a sociedade civil para que sejam criadas estratégias dentro das Unidades Básicas de Saúde - UBS's com o intuito de se combater esse tipo de violência tão comum em nosso meio.

Nesse contexto, a importância de conhecer como a violência ao idoso vem sendo abordada já na formação acadêmica na área da saúde é imprescindível, uma vez que o enfermeiro é o profissional que atua diretamente junto às comunidades e podendo assim proporcionar uma melhor qualidade de vida a essa população através das suas ações de cuidados. 
O trabalho teve como objetivo conhecer o perfil epidemiológico da violência intrafamiliar sofrida pelo idoso no município de Iguatu-Ceará.

\section{Trajeto Metodológico}

Trata-se de um estudo do tipo exploratório, documental, numa abordagem quantitativa baseada na epidemiologia descritiva.

A pesquisa foi realizada no Centro de Referência Especializada de Assistência Social (CREAS), pois é nesse órgão que são encaminhadas as denúncias de maus tratos aos idosos no município de Iguatu-CE.

O critério para obtenção da amostra se deu através da análise das 14 fichas de notificação de maus tratos dirigidos à pessoa idosa localizada no Centro de Referência Especializada de Assistência Social (CREAS).

Os dados foram coletados por meio de uma análise documental no mês de outubro de 2010, após o parecer favorável do Comitê de Ética e Pesquisa da Faculdade Católica Rainha do Sertão (FCRS) de parecer: $n^{\circ}$ 20100150, sendo assegurados os princípios da bioética em concordância com a Resolução 196/96 do Conselho Nacional de Saúde.

É pertinente esclarecer que os dados foram obtidos por um único observador e para garantir o anonimato do sujeito da pesquisa as identificações dos idosos foram feitas por numeração de prontuários através de números seqüenciais e analisados através da utilização de técnicas estatísticas por meio de gráficos.

\section{Análises e Discussão dos Dados}

Com o intuito de alcançar os objetivos propostos nesse trabalho, foi realizada uma análise das 14 fichas de registro de denúncias com a finalidade de conhecer o perfil social dos idosos, identificarem os tipos de violência mais praticadas contra o idoso, identificar os agressores e os responsáveis pelas denúncias.

É pertinente destacar que as informações contidas nos registros e, por conseguinte, necessárias ao desenvolvimento deste estudo, encontravam-se de forma escassa devido ao não preenchimento completo desses registros. 
Os casos notificados de violência apresentam grande importância, pois a violência ganha visibilidade, permitindo o dimensionamento epidemiológico do problema e a criação de políticas públicas voltadas à sua prevenção (SALIBA et al, 2007).

Entre os casos de denúncias registradas nas fichas de ocorrência, a maioria 08, (57\%) foi cometida contra o sexo feminino. Das 14 denúncias, apenas 06 (43\%) foram cometidas contra o sexo masculino. Tal fato vai ao encontro das estatísticas nacionais em relação à violência cometida contra as mulheres, principais vítimas da violência no país, explicado pela fragilidade da mulher e a cultura do machismo, onde o poder do homem é dominante

Uma pesquisa sobre idosos, vítimas de violência, realizada em Belo Horizonte, através da análise de 1388 casos registrados nos "Termos Circunstanciados de Ocorrência" (TCO), no período de 1998 a 2001, revelou que do total de 72,5\% das vítimas que deram queixa, eram mulheres e apenas $27,5 \%$ eram homens. Corrobora a tese de que as mulheres idosas são mais vitimizadas que os homens (MULLER, 2008).

Uma justificativa para esse fenômeno se deve à esperança de vida, que é diferente entre mulheres e homens, ou seja, a expectativa de vida das mulheres é maior do que a dos homens. É a chamada feminilização da velhice. Também, com a viuvêz e as separações, as mulheres assumem os papéis de responsáveis pelas famílias, resultando em mudanças nos arranjos familiares, e na maioria das vezes, ainda em unidades domiciliares unipessoais, fato contrário do que acontece com o homem que tende a casar de novo (MULLER, 2008).

Constatou-se nessa pesquisa que a idade das vítimas de violência intrafamiliar varia de 60 a 90 anos, sendo a faixa etária dos 71 a 80 anos a mais vitimizada com 08 (57\%) casos de denúncia seguida pela faixa de 60 a 70 anos, com 04 (29\%) casos e de 81 a 90 anos, com 02 (14\%) casos.

Tais dados nos levam a perceber que os principais casos de denúncias se referem a pessoas mais velhas, reforçando a idéia de que esta é uma faixa etária de maior fragilidade e, portanto sendo alvo mais fácil para diversos tipos de violência.

A população de idosos no Nordeste com 60 anos ou mais é de 5.441 milhões e com expectativa de vida de 69,7 anos, sendo a pior, quando comparados as demais regiões, como, por exemplo, no sul do país com uma maior expectativa de vida, de 74,2 anos. Quanto ao estado do Ceará, este se configura com uma população de 919.000 idosos com idade de 60 anos ou mais cuja expectativa de vida é de 70,3 anos abaixo da média nacional que é de 72,86 anos (IBGE, 2010 a).

O envelhecimento é um processo da diminuição orgânica e funcional, não decorrente de doença que acontece com o passar do tempo podendo dizer que é um fenômeno natural que apresenta um aumento da fragilidade e vulnerabilidade influenciada com o agravo a saúde e do estilo de vida ${ }^{10}$.

Após a análise minuciosa das 14 fichas de denúncias, foi verificado que a maioria dos idosos era analfabeta - $10(72 \%)$ e apenas $04(28 \%)$ tinham o ensino fundamental incompleto. 
$\mathrm{O}$ analfabetismo nos idosos se torna claro pelos valores obtidos na amostra, fato esse que revela a dificuldade que existia nas décadas passadas, onde a educação não era tão acessível às pessoas, por conta disso o analfabetismo se reflete tão claramente nos idosos atuais.

O nível de educação atual dos idosos é resultado da situação da educação nas décadas de 30 e 40 quando ainda era bastante restrito o acesso a escola, como foi ressaltada na publicação do IBGE (IBGE, 2010b).

Com esta constatação do analfabetismo, tem-se como conseqüência uma maior dependência do idoso no que se tange aos seus cuidados físicos, emocionais, de deslocamento e de administração de suas finanças, no qual em muitos dos casos verificados, seus próprios familiares usufruem do salário do idoso indevidamente, tornando-o assim mais propício a sofrer algum tipo de violência.

Verificou-se no presente estudo que $10(72 \%)$ dos idosos são aposentados, 02 (14\%) são pensionistas e 02 (14\%) não apresentam renda comprovada.

A assistência social, em caráter suplementar, garante a renda mínima de um salário mensal para aqueles que não possam prover o próprio sustento nem tenham familiares que os amparem (FONSECA; GONÇALVES, 203).

Segundo a síntese dos indicadores sociais do IBGE, os idosos contribuem de maneira decisiva para o orçamento da maior parte das famílias brasileiras. Em $53 \%$ dos domicílios do país a contribuição dos idosos com 60 anos ou mais representa mais da metade da renda domiciliar e na região Nordeste a índice é mais elevado, correspondendo a 63,5\%. Quando se fala na zona rural nordestina esse percentual de contribuição no orçamento familiar ainda é mais significativo. Em $73 \%$ dos domicílios da zona rural os idosos têm participação superior a $50 \%$ da renda. Isso implica que o benefício social do idoso na maioria dos casos a acaba sendo a única forma de renda da família (IBGE, 2010 a)

O gráfico seguinte mostra quem são os principais denunciantes de violência intrafamiliar cometida contra a pessoa idosa em Iguatu-CE.

Em primeiro lugar, com 08 registros $(57 \%$,) está o denunciante anônimo, 04 registros $(26 \%)$, são vizinhos, $01(7 \%)$ registro pelo PSF e $01(7 \%)$ registro pela própria pessoa idosa. 
Gráfico 1: Distribuição de sujeitos de acordo com os denunciantes; Iguatu-Ce - 2010.

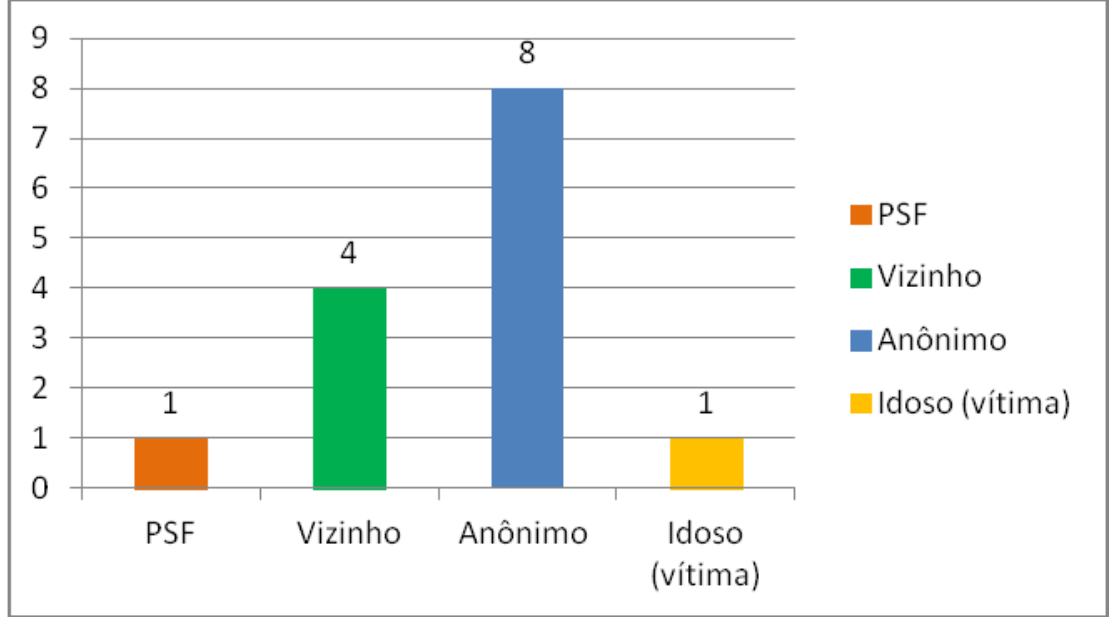

Fonte: Centro de Referência Especializada da Assistência Social (CREAS) - IguatuCE, 2010.

Após os resultados obtidos, pôde-se observar que a grande maiorias das denúncias são realizados por pessoas anônimas e vizinhos correspondendo um total de $12(86 \%)$ das denúncias. Apesar da sociedade não querer se identificar por medo de retaliação por parte do agressor, isso mostra sua indignação e que ela não é conivente com a violência praticada ao idoso.

O anonimato possibilita aquele que vê ou ouve práticas de violência nos arredores de sua residência, a cumprir o papel de atuar na proteção do idoso sem criar confronto direto com a vizinhança (BIDARRA; GREGÓRIO, 2008).

Pode-se verificar também que a denúncia feita pelo próprio idoso se torna pouco presente, dificultando assim seu difícil diagnóstico. Uma das causas que faz com que o idoso não denuncie é o sentimento de culpa e vergonha, medo de ser internado em uma instituição longe do seu laço familiar, medo de retaliação ou represália por parte do agressor, que a maioria das vezes é o próprio filho.

Os idosos têm dificuldades de denunciar os maus tratos que sofrem. Muitos, apesar de afirmarem conhecer, não têm consciência de seus direitos, outras não conseguem se aproximar dos órgãos competentes para denunciar e muitos padecem do medo de denunciar aqueles que os cuidam (SOUZA; FREITAS; QUEIROZ, 2007).

Podemos observar a baixa percepção dos profissionais do Programa Saúde da Família (PSF) de identificar casos de agressão no momento da visita domiciliar realizada ao idoso.

Os problemas que ocorrem no âmbito familiar nem sempre são do conhecimento de outras pessoas, especialmente os profissionais de saúde para que seja realizadas visitas regulares com o intuito de poder conhecer o ambiente e as condições de vida do idoso, como a condição de higiene, condições sociais da família e que seja possível que o profissional de saúde identifique o problema de forma mais adequada para um melhor plano de ação junto a família (NUNES et al, 2002). 
Os profissionais de saúde, pela posição que ocupam na prestação de serviços, são considerados essenciais na identificação de indivíduos e grupos populacionais de risco para a violência e para a execução de iniciativas que promovam a prevenção e as intervenções mais adequadas (SILVA, 2007).

O profissional de saúde, no exercício de suas atribuições, deve adotar suas condutas baseadas em atos morais, guiados por valores éticos (FLORÊNCIO; FERREIRA FILHA; SÁ, 2010).

É preciso despertar e manter a sensibilidade para com os atos de injustiça praticados contra a vida humana, até mesmo prática de negligência, abuso, e desrespeito pelos próprios profissionais de saúde, fato infelizmente comum no cotidiano.

O enfermeiro como ator principal no processo de cuidar desenvolve técnicas de cuidado diferenciado a população idosa visto ser essa população repleta de características orgânicas, psicológicas e sociais próprias. Para tanto, se baseia nos princípios da gerontologia e da geriatria.

A enfermagem gerontológica envolve o cuidado da pessoa idosa e enfatiza a promoção da qualidade de vida e a saúde no mais alto nível possível (ELIOPOULOS, 2005).

Cabe aos profissionais de enfermagem atuar de forma decisiva junto ao idoso e sua família. A assistência deve ter como objetivo a manutenção e a valorização da sua autonomia. Para tanto, é necessário avaliar o grau de dependência e instituir medidas voltadas para o alcance do maior possível de independência funcional e autonomia.

No gráfico seguinte observamos que os maiores agressores das pessoas idosas são parentes entre estes se destaca, lamentavelmente os filhos/filhas, com 06 (43\%) denúncias registradas, genro com 01 (7\%), registro, neto 01(7\%) e $05(36 \%)$ outros familiares. Estes dados revelam que o município de Iguatu-CE segue a tendência nacional de violência cometida contra a pessoa idosa.

Gráfico 02: Distribuição de sujeitos de acordo com os agressores, Iguatu-Ce; 2010.

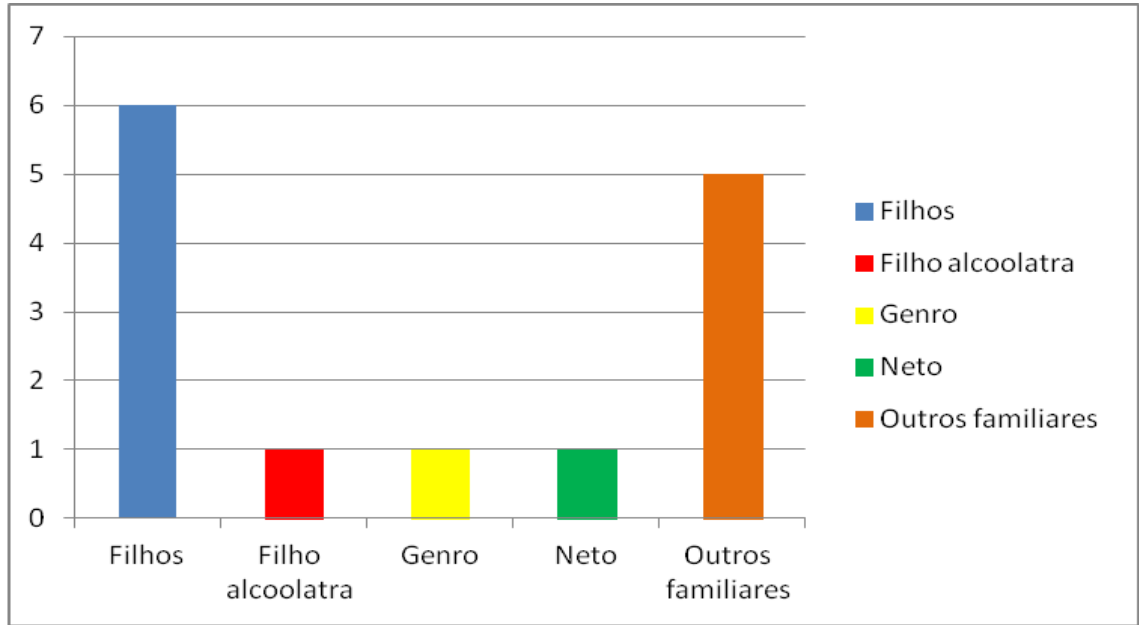

Fonte: Centro de Referência Especializada da Assistência Social (CREAS) - Iguatu-CE, 2010. 
Os maus-tratos de idosos não representam um problema novo. $\mathrm{O}$ abuso é geralmente praticado por pessoas nos quais o idoso deposita confiança: familiares, vizinhos. A vítima é freqüentemente do sexo feminino, com mais de 75 anos e reside com familiares. O perfil desse idoso é convincente de pessoa passiva, impotente, submissa e vulnerável (GUIMARÃES; CUNHA, 2004).

Os fatos mostram que a violência contra o idoso na maioria das vezes é praticada pelos próprios familiares como exemplo os filhos, que são pessoas de sua extrema confiança.

A Constituição Brasileira de 1988 e o Estatuto do Idoso de 2003, os filhos têm o dever de ajudar e amparar os pais na velhice ou enfermidade (PAIM, 2003).

A violência familiar contra idosos é um problema nacional e internacional. Pesquisas feitas em várias partes do mundo revelam que cerca de $2 / 3$ dos agressores são filhos e cônjuges (REAY; BROWNE, 2001).

Na consolidação de dados da Delegacia de Proteção ao Idoso em São Paulo, de acordo com o Instituto Brasileiro de Ciências Criminais, tendo como base 1.500 notificações feitas no período de 1991 a 1998, comprovou que 40\% das queixas dos velhos são contra filhos, netos ou cônjuges e outros 7\% se referem a outros parentes (MINAYO, 2005).

Sobre as situações de risco que as pessoas idosas vivenciam nos seus lares, o autor citado acima, aponta os seguintes dados sobre os sinais de vulnerabilidade e risco, tais como: o agressor vive na mesma casa da vítima; o fato dos filhos serem dependentes financeiramente de seus pais de idade avançada; os idosos dependerem da família de seus filhos para sua manutenção e sobrevivência; o abuso de álcool e drogas pelos filhos, por outros adultos da casa ou pelo próprio idoso; os vínculos afetivos entre os familiares serem frouxos e pouco comunicativos; o isolamento social dos familiares ou da pessoa da idade avançada; o idoso ter sido ou ser uma pessoa agressiva nas relações com seus familiares; haver história de violência na família; os cuidadores terem sido vítimas de violência doméstica; padecer de depressão ou de qualquer tipo de sofrimento mental ou psiquiátrico.

A inexperiência do cuidador, conflitos familiares que o mesmo pode vivenciar estresse, problemas de saúde física e mental, história de abuso sexual, violência familiar, abuso de álcool e drogas e problemas como depressão e ansiedade são, no geral, fatores que estão relacionados aos indivíduos que mais praticam violência nos idosos (GARCIA, 2008).

O uso de drogas lícitas e ilícitas se torna um fator gerador para prática de violência ao idoso devido a sua fragilidade física, motora e cognitiva, tornado-se alvo fácil para que ocorram as agressões.

O abuso do álcool é também um forte agravante da violência física doméstica. A embriaguez patológica é um estado em que à pessoa se torna extremamente agressiva, às vezes nem se lembrando com detalhes o que tenha feito durante essas crises de furor e ira (SOUZA et al, 2008). 
De acordo com a pesquisa podemos constatar que 09 (64\%) idosos convivem com familiares e 05 (36\%) vivem sós.

Neste contexto, percebe que pelo fato de grande parte dos idosos morarem com familiares, estes deveriam lhes dar carinho e atenção, porém, o que se verifica é que, na maioria das vezes, a família faz descaso do idoso, colocando-o na condição de ser inútil e sem valor, mesmo que, muitas vezes, seja o idoso responsável pelo sustento daquela família.

A Constituição Federativa Brasileira faz prevalecer à responsabilidade da família, dispondo que é dever dos filhos o sustento e o cuidado dos pais. Esse dever de filiação, reafirmado tanto na Política quanto no Estatuto do Idoso, exige que filhos maiores e capazes assumam a responsabilidade da prestação de alimentos aos pais que na velhice, por carência ou enfermidade, ficaram sem condições de prover o próprio sustento, principalmente quando se despojaram de bens em favor da prole (FONSECA; GONÇALVES, 2003).

A realidade de violência doméstica e familiar é resultado da cultura de "descarte do velho", em que sua utilidade, após a aposentadoria, se ainda existir, é somente para sustentar os demais filhos e, muitas vezes até netos, com os proventos da Previdência Social. A denúncia dos agressores também se torna para as vítimas idosas algo muito complicado, pois elas residem e não raras vezes dependem dos cuidados destes mesmos agressores (RITT, 2007).

De acordo com os dados no gráfico 03 podemos observar que a violência praticada com mais freqüência aos idosos são: Negligência com 04 (28\%), Física/Negligência com 03 (21\%), Financeira/Negligência com 02 (15\%), Física com 02(15\%), física/Psicológica com 01(7\%), Física/ Financeira com 01(7\%) e Financeira com 01 (7\%).

Após analisar os dados contidos no gráfico, pode-se observar que os idosos na maioria das vezes não sofrem só um tipo de violência ao mesmo tempo, no qual 07 (50\%) dos idosos sofrem mais de um tipo de violência.

Houve uma maior incidência na violência por negligência, caso que vem a ocorrer aos idosos que vivem principalmente só, ocasionados pelo abandono dos familiares e pelo fato de não terem mais a capacidade psicológica, física e motora de se cuidar. 
Gráfico 03: Distribuição de sujeitos de acordo com os tipos de violência sofrida. Iguatu-Ce; 2010.

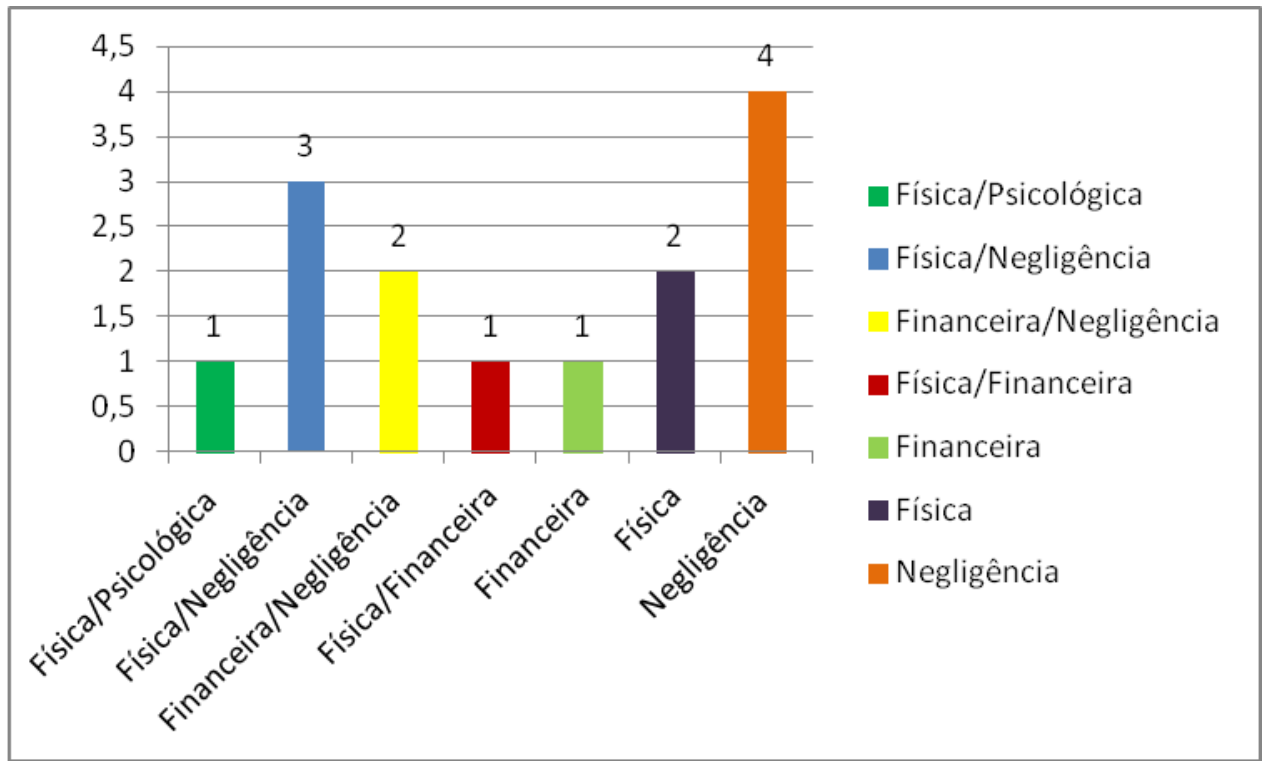

Fonte: Centro de Referência Especializada da Assistência Social (CREAS) - Iguatu-CE, 2010.

Na revisão de estudo sobre a violência contra o idoso, mostra que, há uma década, os Estados Unidos da América (EUA) ainda procuravam uma forma de prevenir, identificar e cuidar da violência conta o idoso, situação que persiste até hoje. De acordo com a autora, em Boston, 32 em cada 1000 pessoas de 65 anos ou mais já sofreram violência física, verbal ou ainda negligência. No Canadá, em cada 1000 idosos 40 já sofreram algum tipo de violência física ou verbal e 25 foram vitimas de exploração financeira (SANCHES; LEBRAO; DUARTE, 2008).

No Brasil, a negligência é uma das formas de violência mais presente tanto no contexto doméstico quanto no plano institucional, resultando freqüentemente em lesões e traumas físicos, emocionais e sociais para com o idoso (SOUZA; FREITAS; QUEIROZ, 2007).

No Ceará, conforme dados da Secretaria da Ouvidoria Geral e do Meio Ambiente (SOMA), entre as denúncias feitas ao Serviço Especial de Defesa do Idoso (SEDI) e Alô-Idoso, em 2004, 32\% dessas denúncias eram de violência física, $20 \%$ de abandono, $16 \%$ de apropriação indébita de aposentadoria e 13\% de negligência (SOUZA; FREITAS; QUEIROZ, 2007).

$\mathrm{O}$ abuso financeiro que antigamente era limitado aos familiares de muitas posses, hoje atinge classes menos privilegiadas da população e traz consequiências desastrosas para o idoso. É comum surgirem pessoas dizendo ter a intenção de ajudar ao idoso nas questões previdenciárias e toma posse do dinheiro do aposentado, em outros casos, a própria familiares força ou induzem a realizar empréstimo consignado, com desconto em folha de recebimento de aposentadoria, que às vezes não 
condizem com a renda do idoso, deixando dessa forma, o idoso praticamente desamparado financeiramente (MEDEIROS, 2005).

Abuso psicológico, violência psicológica ou maus tratos psicológicos, são agressões verbais ou gestuais, chantagem afetiva, desprezo ou privação do poder de decisão com o objetivo de aterrorizar os idosos, humilhá-los, restringir sua liberdade ou isolá-los do convívio social (PAIXÃO JÚNIOR; REICHENHEIMEIM, 2006).

Dos encaminhamentos e cuidados como forma de integralidade da assistência entre as instituições tem-se, no cenário da pesquisa, o seguinte protocolo de assistência: as denúncias são encaminhadas ao CREAS através da UBS, conselho do idoso e denúncias anônimas ou não. Após a denúncia é elaborado um relatório pela equipe multiprofissional formado por psicólogos, assistentes sociais e educadores sociais.

Após essa conduta, a equipe multiprofissional é encaminhada à casa da vítima para averiguar os tipos de maus tratos realizando uma assistência psicossocial dirigida tanto à vítima bem como às suas famílias, onde é elaborado um relatório sobre a situação encontrada e realizados os seguintes encaminhamentos institucionais: abrigo domiciliar, fórum civil e/ou grupos de convivência.

Estes serviços devem funcionar em estreita articulação com os demais serviços da proteção social básica e da especial, com as demais políticas públicas e demais instituições que compõem o Sistema de Garantia de Direitos, no intuito de estruturar uma rede efetiva de proteção social (BRASIL, 2006).

Pode-se observar também a inatividade dos profissionais do programa saúde da família (PSF) em especial o agente comunitário de saúde (ACS) e o enfermeiro por haver uma ligação mais íntima com idoso e sua família. O profissional de enfermagem como sendo o ator principal no processo de cuidar deve desenvolver ações através da visita domiciliar para que possam identificar os fatores de risco para a violência junto ao idoso com o objetivo de manutenção, independência funcional e a promoção da qualidade de vida desse sujeito.

\section{Conclusão}

Com o aumento significativo da expectativa de vida dos brasileiros caracterizado pelo declínio da mortalidade infantil, pela diminuição de morte de adultos por infecção e pelo declínio da taxa de natalidade, vem crescendo a cada ano o número de idosos no país.

Esse crescimento vem acontecendo devido alguns fatores como o avanço nas pesquisas cientificas, acesso aos serviços sócio-sanitário, cura de algumas doenças, investimento das instituições 
públicas no combate as epidemias, as obras de saneamento básico, na melhoria da alimentação básica e na melhoria das moradias.

Juntamente com o envelhecimento da população, a violência contra o idoso vem aumentando por causa do aumento da fragilidade e vulnerabilidade influenciada com o agravo da saúde e do estilo de vida, intensificado pelo déficit auditivo, motor e cognitivo dessa pessoa idosa, ocasionando agravos nos índices de problemas sociais e de saúde pública. E se tornando cada vez mais perceptível devido a uma maior exposição pela mídia com os avanços nas políticas públicas com o estatuto do idoso e entidades de defesa como os conselhos do idoso e etc.

No Iguatu, conforme análise de 14 fichas de registro de denúncias encaminhada ao Centro Referência Especializada da Assistência Social (CREAS) constatou-se que os idosos, na maioria das vezes, não sofrem apenas um tipo de violência e sim variados tipos ao mesmo tempo. Os tipos de ocorrências mais freqüentes são a violência física junto com a negligência no qual as maiores vítimas foram as mulheres, devido a sua fragilidade a e pela cultura ainda dominante do machismo. A baixa escolaridade dos idosos e também a inversão de valores morais em nossa sociedade capitalista que não valoriza o idoso são fatores que contribuem para a prática da violência

No que se refere aos responsáveis pelos atos agressão são os próprios parentes entre estes se destaca lamentavelmente os filhos/filhas que deveriam ser os principais atores de cuidar e zelar pelo bem estar do idoso.

Constatou-se também que a faixa etária mais velha são as mais vitimizadas, reforçando a idéia de que pessoas mais velhas têm maior fragilidade e, portanto constitui alvo fácil para diversos tipos de violência. É pertinente retomar que quanto aos denunciantes, em primeiro lugar tem-se denunciante anônimo mostrando por parte da sociedade sua indignação e que ela não e conivente com a violência praticada ao idoso, seguido por vizinhos, PSF e pela própria pessoa idosa.

Mediante o estudo analisado pôde-se observar que os profissionais do programa saúde da família (PSF) devem cumprir de forma mais ampla seu papel de promotor da saúde utilizando o amor como terapia com idoso e no ato de cuidar da enfermagem. Nesse contexto, precisa ser mais vigilantes para identificar casos de violência no momento da visita domiciliar realizada ao idoso, devido a população idosa ter características biopsicossociais próprias, sendo necessário ser avaliado de forma holística.

Cabe aos profissionais de enfermagem junto com o conselho de defesa do idoso e demais redes sociais atuar de forma decisiva na assistência ao idoso e sua família. A assistência deve ter como objetivo a manutenção e a valorização da sua autonomia. Para tanto, é necessário avaliar o grau de dependência e instituir medidas voltadas para o maior alcance possível de independência funcional. 
Os profissionais de saúde devem estar preparados para diagnosticarem suspeitas ou casos confirmados de maus tratos para, a seguir, trabalharem com o idoso de maneira a lhe informar sobre os danos à saúde, bem como condutas a serem tomadas e orientar sobre os seus direitos.

Em vista dos resultados obtidos neste estudo, acreditamos na necessidade da Unidade Básica de Saúde manter ações de intersetorialidade com as redes sociais como: grupo de idosos, conselho de defesa do idoso, igreja, centros de referencia ao idoso e as demais entidades públicas e do preenchimento por completo das fichas de denúncias por parte do CREAS por apresentar grande importância, pois a violência ganha visibilidade, permitindo o dimensionamento epidemiológico do problema e a criação de políticas públicas voltadas à sua prevenção.

\section{Referências}

ARAÚJO LF, LOBO FILHO JG. Análise psicossocial da violência contra idosos. Psicol. Reflex. Crit., vol.22, n.1, p. 153-160.

BIDARRA ZS, GREGORIO FJ. Configurações da violência psicológica, contra crianças e adolescentes no município de Toledo (PR). Informe Gepec, v. 12, nº. 1, 2008

BRASIL. Secretaria Nacional de Assistência Social. Ministério do Desenvolvimento Social e Combate a Fome. Centro de Referência Especializado de Assistência Social - CREAS: Guia de Orientação $\mathbf{N}^{\mathbf{o}}$ 1. $1^{\circ}$ versão. Brasília-DF, 2006.

ELIOPOULOS C. Enfermagem Gerontológica. 5 ed. Porto Alegre: Editora Artmed, 2005.

FLORÊNCIO MVDL, FERREIRA FILHA MO, SÁ LD. A violência contra o idoso: dimensão ética e política de uma problemática em ascensão. Rev. Eletr. Enf. 2007; 9(3):847-57. Disponível em:< http://www.fen.ufg.br/revista/v9/n3/v9n3a23.htm> acesso em: 24 abr. 2010.

FONSECA MM, GONÇALVES HS. Violência contra o idoso: Suportes legais para a intervenção. Rio de Janeiro-RJ, 2003.

GARCIA SS. Violência intrafamiliar contra idosos: psicopatologia do indiciado. Criciúma - SC, 2008.

GUIMARÃES RM, CUNHA UGV. Sinais e sintomas em geriatria. 2 ed. São Paulo: Atheneu, 2004.

INSTITUTO BRASILEIRO DE GEOGRAFIA E ESTATÍSTICA (IBGE). Censo demográfico de 2000: Perfil dos Idosos Responsáveis pelos Domicílios. Disponível em: <http://www.ibge.gov.br/home/presidencia/noticias/25072002pidoso.htm. Acesso em: 5 out. 2010.

INSTITUTO BRASILEIRO DE GEOGRAFIA E ESTATÍSTICA. Tabuas completas de mortalidade-2007: em 2007, no Brasil a esperança de vida ao nascer era de 72,57\% anos. 01 de 
dezembro de 2008. Disponível em:<http://www.ibge.gov.br/home/presidencia/noticia/noticias> Acesso em: 12 abr. 2010.

MEDEIROS J. Flagrante: golpistas enganam idosos. Jornal O Estado de São Paulo, São Paulo, 23 jun. 2005. Caderno Metrópole, p. C1-C3.

MINAYO MCS. Violência contra o idoso: avesso do respeito à experiência e a sabedoria: Maria Cecília de Sousa Minayo. 2 ed. Brasília. Secretaria Especial dos Respeito Humano, 2005.

MORAES CL, APRATTO JÚNIOR PC, REICHENHEIM ME. Rompendo o silêncio e suas barreiras: um inquérito domiciliar sobre a violência doméstica contra idosos em área de abrangência do Programa Médico de Família de Niterói, Rio de Janeiro, Brasil. Cad. Saúde Pública, Rio de Janeiro, 24(10): 2289-2300, out, 2008.

MULLER EF. A violência intrafamiliar contra o idoso: um estudo no contexto do CIAPREVI Florianópolis/SC. 109 f. Monografia (Graduação em Serviço Social) - Universidade Federal de Santa Catarina, Florianópolis, 2008.

NERI AL, YESSUDA MS, (ORGS); CACHIONI M (colab). Velhice bem-sucedida: aspectos afetivos e cognitivos. 2 ed. Campina-SP: Papirus;2004.

NUNES MO, TRAD LB, ALMEIDA BA, HOMEM CR, MELO MCIC. O agente comunitário de saúde: construção da identidade desse personagem híbrido e polifônico. Cad. Saúde Pública. 2002, vol.18, n.6, pp. 1639-1646.

PAIM SP. Estatuto do Idoso: Dispõe sobre o Estatuto do Idoso, e dá outras providências. Senado Federal Brasília - DF, 2003.

PAIXAO JÚNIOR CM, REICHENHEIM ME. Uma revisão sobre instrumentos de rastreamento de violência doméstica contra o idoso. Cad. Saúde Pública [online]. 2006, vol.22, n.6, pp. 1137-1149.

QUEIROZ SB. Participação Masculina no Programa Idoso Feliz Participa Sempre - PIFPSU3IA/UFAM. Manaus-AM, 2009.

REAY AM, BROWNE KD. Risco características fator de cuidadores que fisicamente abuso ou negligência de seus dependentes idosos. Envelhecimento da Saúde Mental, 5:56-62., 2001.

RITT CF. Violência doméstica e familiar contra o idoso: o município e a implementação das políticas públicas previstas no estatuto do idoso. Santa Cruz do Sul, março de 2007.

SALIBA O, GARBIN CAS, GARBIN AJI, DOSSI AP. Responsabilidade do profissional de saúde sobre a notificação de casos de violência doméstica. Rev. Saúde Pública [online], vol.41, n.3, pp. 472-477. ISSN 0034-8910, 2007.

SANCHES PARA, LEBRAO ML, DUARTE YAO. Violência contra idosos: uma questão nova? Saúde Soc. 2008, vol.17, n.3, pp. 90-100.

SANTOS ACPO, SILVA CA, CARVALHO LS, MENEZES MR. A construção da violência contra idosos. Rev. Bras. Geriatr. Gerontol. v.10 n.1 Rio de Janeiro-RJ, 2007.

SILVA RA. Bem-estar psicológico e adolescência: fatores associados. Cad. Saúde Pública. 2007, vol.23, n.5, pp. 1113-1118. 
7SOUZA ER, PENNAII LHG, FERREIRA AL, TAVARES CMM, SANTOS NCO. Tema Violência Intrafamiliar em Currículos de Graduação em Enfermagem e Medicina. Rev Enferm UERJ, Rio de Janeiro, 2008.

SOUZA JAV, FREITAS MC, QUEIROZ T. A violência contra os idosos: análise documental. Revista Pesquisa Brasileira de Enfermagem REBEn, maio-jun; 60(3):268-72. Brasília-DF, 2007.

\section{Como citar esse artigo (ABNT):}

FERREIRA, Natália B.; CORREIA, Cleiton A.; LUNA NETO, Raimundo T.; NÓBREGA, Riani J.N; CHRISTOFOLINI, Denise M Característica Epidemiológica da Violência Intrafamiliar contra o Idoso no Município de Iguatu - CE. Id on Line Revista de Psicologia, Julho de 2014, vol.8, n.23, p. 179-194. ISSN 1981-1179. 